\title{
IMPLEMENTATION OF THE 9th INTERNATIONAL CLASSIFICATION OF DISEASES:
}

WHO Publication: 'Mental Disorders: Glossary and Guide to their Classification in accordance with the Ninth Revision of the International Classification of Diseases'. (WHO, Geneva, 1978.)

The College has recommended that the WHO Glossary of psychiatric terms should be in general use with the 9th International Classification of Diseases and has asked that the Department of Health and Social Security should support its being made available to all grades of psychiatric staff. (It is hoped in this way to achieve greater consistency in the recording of psychiatric diagnoses on form HMR 1 (Psych. I/P) for the purposes of the Mental Health Enquiry.) The Department of Health and Social Security issued a general letter on 5 April 1979, Ref. SRF/2/88 in which they stated: 'It is hoped that hospital administrations will find it possible to make copies of the glossary available to all grades of psychiatric staff and to administrative and clerical staff in psychiatric records departments'. Copies of the Glossary, which replaces the previous WHO booklet on the 8th Revision of the ICD, are available from HMSO. The price is $£ 4.20$ per copy for orders of less than 50 copies; there is a discount on large orders.

The College hopes that all Fellows and Members will ensure that they and their junior staff are issued with this Glossary. It is a result of several years of collaborative effort between WHO Geneva and psychiatrists from many countries, and is accepted by many countries across the world as a means of national and international statistical comparisons. It also has considerable value as an educational document, since it was put together by representatives of many different viewpoints. Psychiatrists of all grades of experience and expertise should be familiar with the ICD-9 and be able to discuss the ways in which their own views and concepts of diagnosis and classification differ from it.

Thomas BeWLeY

Dean

\section{THE CUTS IN THE NHS}

\section{The College's Statement on Hospital Closures}

At its meeting on 26 October 1979 Council heard of the threatened closure of a number of psychiatric units and related departments and expressed great concern that the current economic situation might seriously threaten the maintenance and development of essential services for the mentally ill and the mentally handicapped. We wish to stress the need for the closest consultation at all levels between administrators and members of the College so that cuts can be made which are effective economically with the least danger of reducing the services to patients. This is particularly important where 'temporary' closures are being considered where the normal consultative processes may be by-passed. Our specialty is recognized as still being relatively underprovided in comparison with other areas of medicine. Furthermore, it relies heavily on manpower and not on expensive apparatus, costly drugs or other resources besides personnel.

The general principles which the College wishes to stress when closures are being considered concern, firstly maintenance of proper training facilities. Training in certain sub-specialty areas of psychiatry can be particularly threatened by the closure or curtailment of a comparatively small number of specialist Institutions. Under particular threat can be the specialist services to pschotherapy, psychogeriatrics and neuropathology. The Royal College of Pathologists join with us in expressing great concern that some facilities for neuropathology in relation to psychiatry should be maintained in this country, in spite of the shortage of consultant neuropathologists in post and the small number of trainees.

Closely linked to the point of training is the College's second concern, namely with so-called supra-Regional Units, that is to say, places which provide highly specialized services whose clientele may come from areas wider even than in the Region in which they are situated. Such centres are particularly liable to cuts by Districts and Areas who may consider that their contribution to the care of patients from their own areas is insufficient to justify their local support.

The College has also written to the Secretary of State seeking his assurance that the general priority for mental health services supported by previous governments will be maintained.

Desmond Pond 